\title{
First record of the Cuban Many-ringed Wormlizard, Amphisbaena barbouri (Squamata: Amphisbaenidae), from an offshore cay
}

\section{Tomás M. Rodríguez-Cabrera ${ }^{1 *}(\mathbb{D})$ and Javier Torres $^{2}$ (i)}

'Sociedad Cubana de Zoología, Cuba.

${ }^{2}$ Department of Ecology and Evolutionary Biology, University of Kansas, Lawrence, Kansas 66045, USA.

*Corresponding author (tomasmichel.rodriguez@gmail.com)

Edited by: Robert W. Henderson. Date of publication: 14 May 2020.

Citation: Rodríguez-Cabrera TM, Torres J (2020) First record of the Cuban Many-ringed Wormlizard, Amphisbaena barbouri (Squamata: Amphisbaenidae), from an offshore cay. Caribbean Herpetology, 72, 1-3.

DOI: $10.31611 /$ ch.72

Amphisbaena barbouri Gans and Alexander, 1962 is a Cuban endemic distributed in the western half of the main island (Rodríguez et al. 2013). This species has been reported at about 15 sites from Pinar del Río to Cienfuegos provinces (Rodríguez et al. 2013; iNaturalist 2020; Fig. 1).

On 10 August 2017 we found an adult $A$. barbouri (173 mm SVL, $14 \mathrm{~mm}$ tail length; Fig. 2) near the biological station at Cayo Galindo (23.2547, -80.8725; 1 m a.s.l.; point 4 in Fig. 1). This key is located towards the westernmost end of the Archipiélago de Sabana-Camagüey cay system, in Martí Municipality, Matanzas Province (Fig. 1). This finding constitutes the first record of the species from an offshore cay. It also represents the northernmost record, just $4 \mathrm{~km}$ southeast of the northernmost point of the Cuban archipelago (i.e., Cayo Cruz del Padre). The distribution of $A$. barbouri is now extended about $75 \mathrm{~km}$ east-northeast of Matanzas, the nearest published record (Gans \& Alexander 1962).

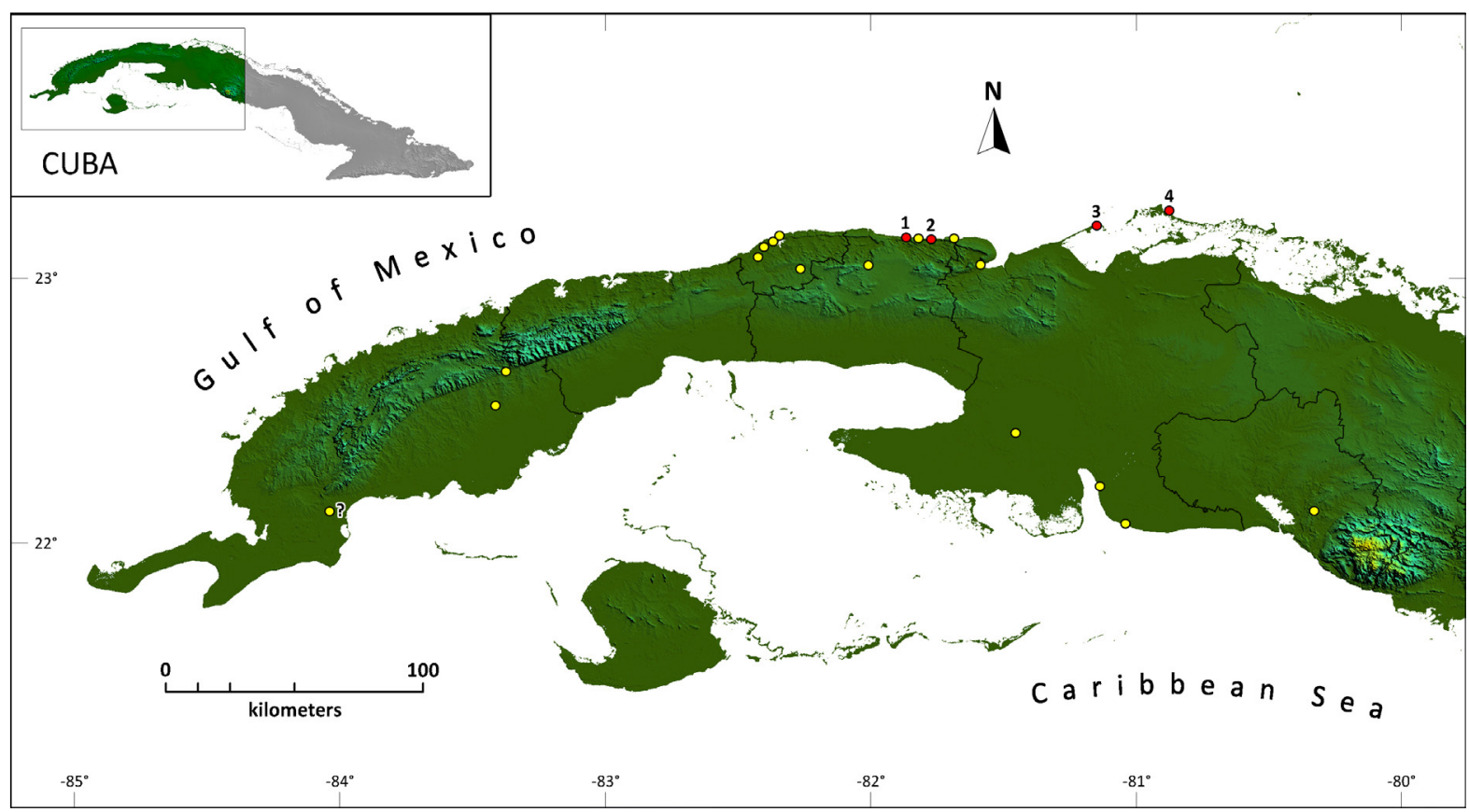

Figure 1. Distribution of Amphisbaena barbouri, including records from the literature (yellow dots) and this paper (red dots). Locality numbers in the text. The question mark (?) represents a published record that needs confirmation (i.e., "San Ubaldo-Sabanalamar" Flora Reserve; Rodríguez et al. 2013). 
The individual was collected by day under a coralline rock in dry, thorny shrubwood on limestone, at about $30 \mathrm{~m}$ from the shoreline. It had 230 body annuli, 17 caudal annuli, 4 precloacals, 13 dorsal midbody segments, and 18 ventral midbody segments, diagnostic of A. barbouri (Gans \& Alexander 1962; Thomas \& Hedges 1998). The coloration in life was medium brown (Fig. 2). The voucher specimen is deposited in the zoological collection of the Instituto de Ecología y Sistemática, La Habana, Cuba (CZACC 4.13101).

Other new locality records from this work are indicated by numbers in Fig. 1. MAYABEQUE Province. Santa Cruz del Norte Municipality: (1) Peñón del Fraile (23.1487, -81.8650) and (2) Loma de Canasí (23.1443, -81.7735). MATANZAS Province. Varadero Municipality: (3) "Varahicacos" Protected Landscape (23.1961, -81.1552).

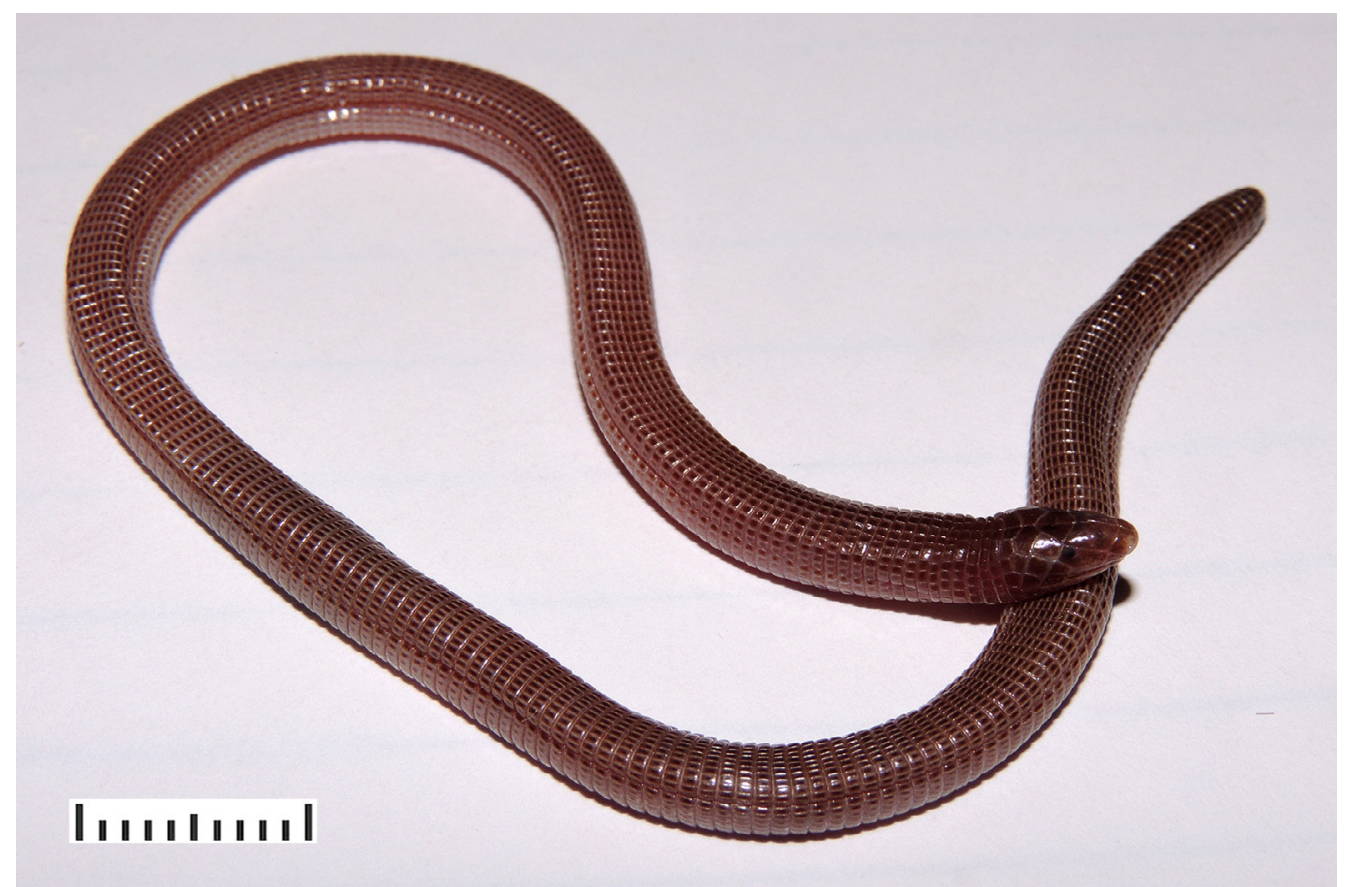

Figure 2. Amphisbaena barbouri from Cayo Galindo, the first offshore record of the species. Scale bar in millimeters. Photo by E. Morell Savall.

The westernmost record of Amphisbaena barbouri at "San Ubaldo-Sabanalamar" Flora Reserve is based on the species list of an unpublished action plan of the area (Rodríguez et al. 2013; question mark in Fig. 1). Identification of amphisbaenian species requires scale counts (Gans \& Alexander 1962; Thomas \& Hedges 1998). This and other records referred to $A$. cubana, a similar species occurring in the same region, might be misidentifications that require confirmation (Schwartz \& Henderson 1991).

\section{Acknowledgments}

We thank the administration and staff of the Empresa Nacional para la Protección de la Flora y la Fauna from Matanzas Province and the production team "Habitat" (Instituto Cubano de Radio y Televisión) for field assistance and logistical support. Manuel Iturriaga verified the species identity.

\section{References}

Gans C, Alexander AA (1962) Studies on amphisbaenids (Amphisbaenia, Reptilia). 2. On the amphisbaenids of the Antilles. Bulletin of the Museum of Comparative Zoology, 128, 65-158.

iNaturalist (2020) iNaturalist. Available from https://www.inaturalist.org/observations/19346897. Accessed 23 April 2020. 
Rodríguez Schettino L, Mancina CA, Rivalta González V (2013) Reptiles of Cuba: Checklist and geographic distribution. Smithsonian Herpetological Information Service, 144, 1-96.

Schwartz A, Henderson RW (1991) Amphibians and Reptiles of the West Indies. Descriptions, Distributions, and Natural History (University of Florida Press, Gainesville).

Thomas R, Hedges SB (1998) A new amphisbaenian from Cuba. Journal of Herpetology, 32, 92-96. 